\title{
A self report measure of affective lability
}

Stan R Moore, Louise S Gresham, Mark B Bromberg, Edward J Kasarkis, Richard A Smith

\begin{abstract}
Objectives-The development and validation of the Center for Neurologic StudyLability Scale (CNS-LS), the first self report measure of affective lability in patients with amyotrophic lateral sclerosis (ALS).

Methods-Potential questionnaire items were identified through interviews with patients and families and expert review. Potential items, as well as measures of affect intensity, affective lability in psychopathology, and depression were administered to 99 patients with ALS for item selection and the examination of factor structure and construct validity. Testretest reliability was examined using an additional sample of 31 patients with ALS, and criterion related validity was examined by comparing CNS-LS scores with physicians' diagnoses of affective lability in a sample of 77 patients with ALS.

Results-A seven item questionnaire emerged, composed of two subscales measuring labile laughter (four items) and labile tearfulness (three items). The CNS-LS showed a pattern of associations with affect intensity, affective lability in psychopathology, and depression consistent with a scale measuring affective lability. The CNS-LS also showed good testretest reliability and internal consistency, and successfully predicted physicians' diagnoses of affective lability. An auxiliary subscale measuring labile frustration, anger, and impatience also emerged.

Conclusions-The CNS-LS is a short, easily administered, and psychometrically sound measure of affective lability for use with patients with ALS. It has potential applications as both a clinical screening device and a research tool. The need for future research into the relation of depression as well as labile frustration, anger, and impatience to the syndrome of affective lability in neurological disorders is discussed.
\end{abstract}

\section{(F Neurol Neurosurg Psychiatry 1997;63:89-93)}

Keywords: amyotrophic lateral sclerosis; affective lability; emotional lability; pathological laughter and crying; pseudobulbar emotionality

Correspondence to: Dr Stan R Moore, Center for Neurologic Study, 11211 Sorrento Valley Road, Suite H, San Diego, CA 92121, USA

Received 12 April 1996 and in final revised form 9 January 1997

Accepted 23 January 1997 preponderance, and runs its fatal course in two to three years. Whereas the brunt of the pathological process occurs in the motor cortex, spinal cord, and brainstem, there may also be bilateral involvement of corticobulbar tracts that project on the brainstem.

Along with depression many patients with ALS have sudden outbursts of uncontrollable laughter or tearfulness known variously as affective or emotional lability, pseudobulbar emotionality, or pathological laughter and crying. $^{2-5}$ Such outbursts can occur spontaneously or in response to provocative stimuli such as questions or events. In many cases these displays are dissociated from the patient's underlying mood or emotions, although a lack of consensus as to whether this is necessarily the case is shown by frequent use of both the terms affective lability and emotionalism in the literature.$^{6-8}$ Irrespective of its origins, this syndrome can have problematic social consequences. These depend to an extent on the frequency and intensity of the behaviour, and in the most extreme cases affective lability can be disabling, primarily due to the stigma attached to loss of emotional control. A body of evidence suggests that labile affect can often be modulated through pharmacological intervention. ${ }^{910}$

The basic mechanisms underlying affective lability are not well understood. It is known that lesions in various areas in the brain including the frontal and temporal lobes, putamen, and brain stem are all associated with the occurrence of pathological laughter or tearfulness. ${ }^{11}$ Whereas this syndrome is most often seen in disorders such as stroke, multiple sclerosis, and ALS, it can occur in association with many other neurological disorders. Presumably, any pathological process that interrupts cortical inhibition of the brain stem may result in this behaviour; thus affective lability can be considered a disconnection syndrome.

Studies have suggested that pathological affect occurs in $27 \%$ to $49 \%$ of patients showing bulbar symptoms of ALS. ${ }^{12-14}$ Research examining the prevalence and incidence of this syndrome has been hampered by the lack of a reliable assessment instrument, with previous studies relying on unstructured interviews, patient records, and non-validated questionnaires. An important first step in the accurate measurement of affective lability syndrome has been accomplished with the pathological laughter and crying scale, an interviewer administered rating scale validated for use with stroke victims. ${ }^{15}$ Another related development has been the affective lability scale, which measures labile mood and affect in the context of personality and psychopathology. ${ }^{16}$ 
There remains the need for a short, easy to administer, self report measure of affective lability that has been validated for use with patients with ALS. The following study was conducted for the purpose of developing and validating such a measure-the Center for Neurologic Study-Lability Scale (CNS-LS). This study included four groups of patients, and we anticipated that in its final form the CNS-LS would provide a score for overall affective lability incorporating subscores for labile laughter and labile tearfulness.

\section{Methods}

Item generation included interviews with 10 patients with ALS identified by their physicians as having affective lability or loss of emotional control. Whenever possible, each patient's immediate family members were also interviewed. Participants were asked to identify specific thoughts, feelings, behaviours, and situations that might be associated with this phenomenon. Responses were then used to construct potential questionnaire items. Items were submitted to five neurologists familiar with both ALS and affective lability for review and suggestions. Fifty seven items were chosen by at least two of the five experts as relevant to the syndrome of affective lability in ALS and these items were retained. In its final form, each item asks respondents to indicate on the following five point scale how often they experience symptoms of affective lability: 1 (applies never), 2 (applies rarely), 3 (applies occasionally), 4 (applies frequently), 5 (applies most of the time).

For the purposes of item selection and the examination of factor structure and construct validity, the 57 potential questionnaire items were administered to 99 patients with ALS recruited from six ALS research and treatment centres in the United States and Canada. The mean age of participants was 57.79 (SD 13.38) years, and 69 were male. Construct validity of the CNS-LS was examined by determining its convergent and discriminant relations with three other measures. Fifty five of the 99 participants completed the anxiety, depression, and anger subscales of the affective lability scale. To the degree the constructs of affective lability in psychopathology and affective lability in ALS overlap, especially symptomatically, the CNS-LS and the affective lability scale should be associated. Thirty five participants completed the affect intensity measure, a measure of the intensity with which an individual experiences affects in general. ${ }^{17}$ Previous research has shown the intensity of affect to be unrelated to labile affect and mood. ${ }^{18}$ Seventy two participants completed the Beck depression inventory, a widely used measure of state depression. ${ }^{19}$ Previous studies examining the relation between affective lability and mood disorder have focused on stroke patients, producing mixed results. ${ }^{2021}$ As a result, no predictions were made regarding the relation of depressed mood to the CNS-LS, although it was expected that if an association were present it would be between depression and the portion of the CNS-LS measuring labile tearfulness.
To assess test-retest reliability, the final version of the CNS-LS that emerged after item selection was administered to 31 patients with ALS recruited from the Center for Neurologic Study, San Diego, California, at one to two week intervals. The mean age of participants was 61.81 (SD 13.21) years, and 21 were male.

To determine criterion related validity, 77 patients with ALS, 51 from the Center for Neurologic Study and 26 from the University of Kentucky, also completed the final version of the CNS-LS. The mean age of participants was 55.21 (SD 14.10) years, and 47 were male. A neurologist (one for the Center for Neurologic Study sample, and one for the University of Kentucky sample) diagnosed each participant for presence or absence of labile affect based on both clinical history and neurological examination. Criteria for the diagnosis of lability were sudden outbursts of laughter, crying, or other strong affect that occurred spontaneously, or were inappropriate given the context.

\section{Results}

ITEM SELECTION AND FACTORIAL STRUCTURE Factor structure of the 57 potential questionnaire items was examined using principal components analysis with varimax rotation. Scree slope analysis (see end note 1 ) identified three underlying factors, accounting for $76.6 \%$ of the variance. Factor 1 accounted for $49.7 \%$ of the variance and consisted of eight items that assess labile frustration, impatience, and anger. Factor 2 contained four items, which accounted for $16.7 \%$ of the variance, and these were conceptually related to pathological laughter. Factor 3 contained three items assessing labile tearfulness and accounted for $10.2 \%$ of the variance.

The construct of affective lability has up to now encompassed the symptoms of both pathological laughter and pathological tearfulness, but not the labile expression of anger, frustration, or impatience. Therefore, it was decided for theoretical reasons that factor 2 , measuring labile laughter and factor 3 , measuring labile tearfulness, should be retained as separate subscales comprising the seven item CNS-LS. Factor 1, measuring a combination of labile frustration, anger, and impatience, was retained as an auxiliary subscale for the purpose of exploring the relevance of these symptoms to affective lability in ALS (See appendix A and appendix B for factor 1 items and psychometric values).

A second principal components analysis was performed on the seven items comprising the CNS-LS. Two factors emerged, identical in item content to the labile laughter and tearfulness subscales identified in the previous analysis, and together these accounted for $80.2 \%$ of the total variance. The factor containing the four labile laughter subscale items accounted for $56.4 \%$ of the variance, whereas the factor containing the three items from the labile tearfulness subscale accounted for $23.9 \%$ of the variance. Tables 1 and 2 present the resulting seven items and factor loadings. Table 3 gives the factor eigenvalues and percentages of variance. 
Table 1 Items composing labile laughter subscale

\begin{tabular}{ll}
\hline & $\begin{array}{c}\text { Factor } \\
\text { loading }\end{array}$ \\
\hline I find that even when I try to control my laughter I & 0.83 \\
$\quad$ am often unable to do so & 0.80 \\
$\begin{array}{l}\text { I find that I am easily overcome by laughter } \\
\text { There are times when I won't be thinking of } \\
\text { anything happy or funny at all, but then I'll } \\
\begin{array}{l}\text { suddenly be overcome by funny or happy } \\
\text { thoughts }\end{array}\end{array}$ \\
$\begin{array}{l}\text { Others have told me that I seem to become amused } \\
\text { very easily or that I seem to become amused } \\
\text { about things that really aren't funny }\end{array}$ & 0.79 \\
\hline
\end{tabular}

Table 2 Items composing labile tearfulness subscale

\begin{tabular}{ll}
\hline & $\begin{array}{l}\text { Factor } \\
\text { loading }\end{array}$ \\
\hline $\begin{array}{l}\text { I find myself crying very easily } \\
\text { There are times when I feel fine one minute, and } \\
\text { then I'll become tearful the next over something } \\
\text { small or for no reason at all }\end{array}$ & 0.65 \\
$\begin{array}{l}\text { I find that even when I try to control my crying I } \\
\text { am often unable to do so }\end{array}$ & 0.59 \\
\hline
\end{tabular}

Table 3 Eigenvalues and percentages of variance for CNS-LS

\begin{tabular}{lll}
\hline Factor & Eigenvalue & $\begin{array}{l}\text { Percentage of } \\
\text { variance }\end{array}$ \\
\hline Labile laughter & 3.95 & 56.4 \\
Labile tearfulness & 1.67 & 23.9 \\
\hline
\end{tabular}

Cronbach's $\alpha$ was used to measure internal consistency of the CNS-LS, with a resulting coefficient of 0.91 for the laughter subscale, 0.89 for the tearfulness subscale, and 0.87 for the entire questionnaire.

\section{CONSTRUCT VALIDITY}

Table 4 shows that as predicted, total scores for the seven item CNS-LS were significantly associated with the affective lability scale $(r=$ $0.41, \mathrm{P}<0.01)$. As also predicted, the CNS-LS showed no association with affective intensity measure scores $(P>0.05)$. The CNS-LS was significantly associated with Beck depression inventory scores $(r=0.24, \mathrm{P}<0.05)$. As would be expected, the tearfulness subscale of the CNS-LS showed an association with Beck depression inventory scores $(r=0.39, \mathrm{P}<0.01)$, whereas the laughter subscale did not.

Table 4 Correlations between CNS-LS and the affective lability scale, Beck depression inventory, and affective intensity measure

\begin{tabular}{|c|c|c|c|}
\hline & $\begin{array}{l}\text { Affective } \\
\text { lability scale }\end{array}$ & $\begin{array}{l}\text { Beck depression } \\
\text { inventory }\end{array}$ & $\begin{array}{l}\text { Affect intensity } \\
\text { measure }\end{array}$ \\
\hline \multicolumn{4}{|l|}{ CNS-LS: } \\
\hline Labile laughter subscale & -0.01 & 0.00 & 0.07 \\
\hline Labile tearfulness subscale & $0.57^{\star \star}$ & $0.39 \star \star$ & -0.06 \\
\hline Total score & $0.41^{\star \star}$ & $0.24^{\star}$ & 0.05 \\
\hline
\end{tabular}

${ }^{\star} \mathrm{P}<0.05 ;{ }^{\star \star} \mathrm{P}<0.01$.

Table 5 Frequency of level of depression as measured by Beck depression inventory as a function of presence or absence of affective lability as measured by CNS-LS

\begin{tabular}{llll}
\hline & \multicolumn{2}{l}{ Beck depression inventory } \\
\cline { 2 - 4 } CNS-LS & $\begin{array}{l}\text { Normal-mild } \\
(0-18)\end{array}$ & $\begin{array}{l}\text { Moderate-severe } \\
(19-29)\end{array}$ & $\begin{array}{l}\text { Extremely severe } \\
(30-60)\end{array}$ \\
\hline $\begin{array}{l}\text { Non-labile (0-10) } \\
\text { Labile (11-35) }\end{array}$ & 24 & 3 & 3 \\
\hline
\end{tabular}

TEST-RETEST RELIABILITY

CNS-LS total scores showed a test-retest reliability of 0.88 .

\section{CRITERION VALIDITY}

Physicians rated 46 of 77 participants as showing meaningful symptoms of affective lability, with the remaining 31 participants showing few or no symptoms of lability. Mean CNS-LS total scores were significantly higher in the labile group (18.46 (SD 6.32)) than in the non-labile group $(10.19(\mathrm{SD} 3.45))(t(75)=$ $6.64, \mathrm{P}<0.001)$. In addition, mean tearfulness subscale scores were significantly higher in the labile group (9.67 (SD 3.31)) than in the nonlabile group $(4.45 \mathrm{SD}(1.88))(t(75)=7.98$, $\mathrm{P}<0.001)$, and mean laughter subscale scores were significantly higher in the labile group (8.76 (SD 4.34)) than in the non-labile group $(5.74(\mathrm{SD} 2.27))(t(75)=3.56, \mathrm{P}=0001)$. Cutting scores for the identification of affective lability using CNS-LS total scores were designated, and categorisations based on these scores were compared with neurologists' diagnoses for the purpose of examining criterion related validity. A cutting score of 13 and above was chosen for situations in which the CNS-LS is to be used for general research purposes because it provided the highest incremental validity (see end note 2). Using this cut off CNS-LS total scores accurately predicted neurologists' diagnoses for $82 \%$ of participants in the current sample, with a sensitivity of 0.84 and a specifity of 0.81 . Assuming a prevalence rate for affective lability between $27 \%$ and $49 \%$ this resulted in an incremental validity ranging from 0.34 to 0.31 and a negative predictive value ranging from 0.92 to 0.84 . The less stringent cutting score of 11 and above was chosen for instances when the CNS-LS is to be used for clinical screening and this cut off predicted neurologists' diagnoses with a sensitivity of 0.91 and a specificity of 0.71 . This results in an incremental validity ranging from 0.27 to 0.26 and a negative predictive value ranging from 0.96 to 0.90 .

Using a cutting score of 13 and above the data set used for item selection and the examination of factor structure and construct validity was reanalysed for the purpose of exploring further the relation between affective lability as measured by the CNS-LS and depression. Table 5 indicates that 66 patients completed both the CNS-LS and the Beck depression inventory, with 36 of these scoring in the labile range on the CNS-LS, and 30 scoring in the non-labile range. Further inspection showed that 11 of 36 (31\%) labile patients had significant levels of depression on the Beck depression inventory, compared with six of $30(20 \%)$ non-labile patients.

\section{Discussion}

The research reported here has resulted in the development and validation of the CNS-LS, the first self report measure of pathological affect for use with patients with ALS. The CNS-LS is short (seven items), easy to administer, and provides a quantitative measure of perceived frequency of affective lability incorporating 
subscales measuring labile laughter and labile tearfulness. It shows high internal consistency and test-retest reliability. In addition, the CNS-LS successfully predicts neurologists' diagnoses of affective lability and shows a convergent and discriminant pattern of relations with affect intensity and affective lability in psychopathology that is consistent with an instrument that is measuring labile laughter and tearfulness.

Little is currently known about the relation between mood and affective lability in ALS. In our sample, CNS-LS scores showed a modest but significant correlation with depression scores. Our own clinical findings suggest that the psychological and interpersonal consequences of loss of affective control can often be a considerable source of distress to both patients and their families, and for this reason an association between the CNS-LS and depression is not surprising. In addition, both affective lability and depressed mood are significantly associated with ALS, and for this reason alone it would not be surprising if affective lability and depression were in turn themselves associated. On the other hand, drugs that are useful in reducing affective lability typically produce significant effects within a matter of days, whereas pharmacological interventions for depression typically require weeks to achieve significant results, a discrepancy that argues against a syndromal association between affective lability and depression. ${ }^{910}$ Several methodological factors in particular limit the interpretability of the current study regarding this topic. For example, the number of participants assessed for both affective lability and mood was small, and because complete medical histories were not available in all cases it is possible that some participants in this study had a pre-existing depression, or were receiving antidepressant or other mood altering medications. In addition, because of methodological limitations it was necessary to use a self report measure of depression, the Beck depression inventory, even though several of its items may confound the measurement of depressed mood with behavioural and physical limitations which are common among those with ALS. It is important to note that from a psychometric perspective the association noted between CNS-LS scores and depression has little practical effect on the utility of our scale as variability in depression scores accounted for only $6 \%$ of the variance in CNS-LS scores in the sample examined. More carefully controlled research into the relation between affective lability and depressed mood in ALS is required.

As with depressed mood, the possible role of labile frustration, anger, and impatience in affective lability in ALS is also unclear. In the course of interviewing patients and their families the symptoms of labile frustration, anger, and impatience were often mentioned in conjunction with the syndrome of affective lability. Items measuring these symptoms were included in our original item pool because they were judged by at least two of five neurologists familiar with affective lability and ALS as being relevant to this syndrome. Further, research with patients with ALS using the CNS-LS has indicated that a combination of the drugs dextromethorphan and quinidine is effective in reducing scores on the auxiliary subscale measuring labile frustration, anger, and impatience as well as the labile laughter and tearfulness subscales. This provides further evidence for a syndromal association between these factors. ${ }^{10}$ Robinson et al also recognised the possible role of labile anger in affective lability by incorporating an item assessing that symptom in their pathological laughter and crying scale. Psychometric data for the auxiliary subscale, however, provides only mixed support for the proposition that labile frustration, anger, and impatience are indeed components of affective lability in ALS. Whereas auxiliary subscale scores were significantly correlated with physicians' diagnoses, they were more strongly correlated with depression. Further, when auxiliary subscale scores were added to the CNS-LS this led to reductions in both its correlation with physicians' diagnoses, and its predictive utility, although this may be the result of a failure on the part of physicians to take the symptoms of labile frustration, anger, and impatience into account when diagnosing affective lability. More research is needed into the possible role of labile frustration, anger, and impatience in the syndrome of affective lability in ALS.

As the first self report measure of affective lability validated for use with neurological patients the CNS-LS has both research and clinical applications. Its ability to accurately determine the presence or absence of affective lability should facilitate research into the prevalence and incidence of this syndrome, whereas also providing a simple, convenient, and reliable dependent measure for use in treatment outcome studies. Because of its ability to accurately identify patients with ALS who are demonstrating symptoms of lability the CNS-LS is attractive as a screening device as well. In this regard it is noteworthy that the CNS-LS classified as affectively labile a number of patients identified as normal by physician diagnosis. Whereas these cases may represent false positives, they also raise the possibility that the CNS-LS may be useful in identifying patients with affective lability who would otherwise go undetected by diagnostic interview alone. It may also identify as affectively labile patients who would otherwise be misdiagnosed with depression or other psychiatric disorders. It is hoped that future studies will examine the validity of the CNS-LS for multiple sclerosis and stroke patients. Such studies may also clarify the degree to which the expression of labile affect is similar or dissimilar across various neurological disorders.

We are grateful to the following benefactors of the Center for Neurologic Study: Tai-Lang Chin, Susan and Charles Donnely, Nancy Fitzpatrick, Evelyn Harshman, Edward and Madeline Kane, Fred and Evelyn Kyler, Gerald and Evelyne Landsberg, George and Joan Thagard, The Thagard Foundation, Dr Ron Tuttle, Lester and Mildred Weisz, and William C M Wong. We are also grateful to Dr Ronald E Smith, and Eulalee G Nasman for comments on an earlier version of this manuscript. 


\section{End notes}

(1) Scree analysis is a widely used method for extracting meaningful factors after factor analysis. ${ }^{22} 23$ This technique involves plotting the slope of factor eigenvalues. The plot line will typically break or deviate sharply at some point, with meaningful factors falling to the left of the break and less meaningful factors falling to the right. Visual inspection then allows identification of those factors that are meaningful.

(2) Incremental validity represents the extent to which a test increases decision making accuracy compared with decisions made using base rate information alone. ${ }^{24}$ Incremental validity is calculated by subtracting the base rate from the positive hit rate- that is, true positives divided by total positives.

\section{Appendix 1: Items composing auxiliary} subscale

\begin{tabular}{|c|c|}
\hline & $\begin{array}{l}\text { Factor } \\
\text { loading }\end{array}$ \\
\hline $\begin{array}{l}\text { People have told me at times that I seem to get } \\
\text { upset very easily or that I get upset over little } \\
\text { things }\end{array}$ & 0.87 \\
\hline I've noticed that I get upset very easily & 0.82 \\
\hline $\begin{array}{l}\text { Others have told me that I seem to get frustrated } \\
\text { very easily or that I seem to get frustrated over } \\
\text { little things }\end{array}$ & 0.81 \\
\hline $\begin{array}{l}\text { I can quickly go from feeling calm to feeling very } \\
\text { angry over little things or for no reason at all }\end{array}$ & 0.79 \\
\hline $\begin{array}{l}\text { At times I can be feeling no more impatient than } \\
\text { others but then I'll suddenly become very } \\
\text { impatient over something small or for no reason } \\
\text { at all }\end{array}$ & 0.76 \\
\hline $\begin{array}{l}\text { People have told me at times that I seem to get } \\
\text { impatient very easily or that I seem to get } \\
\text { impatient over little things }\end{array}$ & 0.76 \\
\hline $\begin{array}{l}\text { Others have told me that I seem to get nervous } \\
\text { very easily or that I seem to become nervous over } \\
\text { little things }\end{array}$ & 0.75 \\
\hline $\begin{array}{l}\text { Sometimes I can be feeling fine one minute and } \\
\text { then I'll yell or raise my voice in an angry way } \\
\text { the next }\end{array}$ & 0.67 \\
\hline
\end{tabular}

\section{Appendix 2:}

The eight item auxiliary subscale presented in appendix showed an internal consistency of 0.86 . It was significantly correlated with the affective lability scale $(r=0.72, \mathrm{P}<0.001)$ and the Beck depression inventory $(r=0.59, \mathrm{P}<0.001)$, but not the affect intensity measure $(r=0.10)$. Auxiliary subscale scores were significantly higher in the labile group (mean 18.04 (SD 6.47)) than in the non-labile group (mean 14.48 (SD 6.41)) ( $t$ $(75)=2.38, \mathrm{P}=0.02$ ).

When auxiliary subscale scores were combined with laughter and tearfulness subscale scores the resulting 15 item scale showed an internal consistency of 0.92 , and a test-retest reliability of 0.88 . Total scores for this version were highly correlated with both the affective lability scale $(r=0.70, \mathrm{P}<0.001)$ and the Beck depression inventory $(r=0.51, \mathrm{P}<0.001)$, but not the affect intensity measure $(0.09)$. Total scores were significantly higher in the physician diagnosed labile group (mean 36.50 (SD 10.57)) than in the non-labile group (mean 24.68 (SD 8.08$)$ 1 $(75)=5.27, \mathrm{P}<0.001$ ) A cuting (mean 24.68 ). A cutting score of 27 or the highest incremental validity. This cut off predicted diagnoses with a sensitivity of 0.74 and a specificity of 0.80 . Based on population base rates ranging from $27 \%$ to $49 \%$, this combina-
tion showed an incremental validity ranging from 0.30 to 0.29 , and a negative predictive value from 0.90 to 0.76 .

1 Tandan R, Radley WG. Amyotrophic lateral sclerosis part I: clinical features, pathology, and ethical issues in management. Ann Neurol 1985;18:271-80.

2 McDonald ER, Wiedenfeld SA, Hillel A, Carpenter CL, Walter RA. Survival in amyotrophic lateral sclerosis. Arch Neurol 1994;51:17-23.

3 Black DW. Pathological laughter: a review of the literature. $f$ Nerv Ment Dis 1982;170:67-71.

4 Davison C, Kelman H. Pathologic laughing and crying. Arch Davison C, Kelman H. Pathologic lau
Neurol Psychiatry 1939;42:595-643.

5 Wilson SAK. Some problems in neurology II. Pathological Wilson SAK. Some problems in neurology II. Pathological
laughing and crying. $\mathcal{F}$ Neural Psychopathol 1923;4:299laugh.

6 Hanger HC. Emotionalism after stroke. Lancet 1993; 342:1235-6.

7 Sloan RL, Brown KW, Pentland B. Fluoxetine as a treat ment for emotional lability after brain injury. Brain Injury 1992;6:315-9.

8 Allman P, Hope RA, Fairburn CG. Emotionalism following brain damage: a complex phenomenon. Postgrad Med $\mathcal{F}$ 1990;66:818-21.

9 Smith RA, Licht JM, Manley PE, Girten B, Tuttle R. Testing the limits of palliative care. In: Rose CJ, ed. $A L S$ from Charcot to the present and into the future. London: Smith-Gordon, 1994:315-24.

10 Smith RA, Moore SR, Gresham LS, Manley PE, Licht JM. The treatment of affective lability in ALS patients with The treatment of affective lability in ALS patients with
dextromethorphan. Neurology 1995;45(suppl 4):A330.

11 Poeck K. Pathophysiology of emotional disorders associated with brain damage. In: Vinken PJ, Bruyn GW, eds. Handbook of clinical neurology. Amsterdam: North-Holland, 1969;3:343-67.

12 Gallagher JP. Pathologic laughter and crying in ALS: a search for their origin. Acta Neurol Scand 1989;80:114-7.

13 Ironside R. Disorders of laughter due to brain lesions. Brain 1956;79:589-609.

14 Mueller R. Progressive motor neuron disease in adults. Acta Psychiatric Neurologica Scandinavica 1952;227:37-56.

15 Robinson RG, Parikh RM, Lipsey JR, Starkstein SE, Price TR. Pathological laughing and crying following stroke: validation of a measurement scale and a double-blind treatment study. Am f Psychiatry 1993;150:286-93.

16 Harvey PD, Greenburg BR, Serper MR. The affective lability scales: development, reliability, and validity. F Clin Psyity scales: development
chol 1989;45:786-93.

17 Larsen RJ, Diener E, Emmons RA. Affect intensity and reaction to daily life events. F Pers Soc Psychol 1986;51:80314

18 Larsen RJ, Diener E. A multitrait-multimethod examination of affect structure: hedonic level and emotional intensity. Personality and Individual Differences 1985;6:631-6.

19 Beck AT, Ward CH, Mendelson M, Mock J, Eraugh J. An inventory for measuring depression. Arch Gen Psychiatry 1961;4:561-71.

20 House A, Dennis M, Molyneaux A, Warlock C, Hawton K. Emotionalism after stroke. BMf 1989;298:991-4.

21 Morris PLP, Robinson G. Raphael B. Emotional lability after stroke. Aust NZ F Psychiatry 1993;27:601-5.

22 Jones PB, Sabers DL. Examining test data using multivariate procedures. In: Zeidner M, Most R. eds. Psychological testing: an inside view. Palo Alto, CA: Consulting Psychologists Press, 1992:305.

23 DeVellis RF. Scale development: theory and applications. Newbury Park, CA: Sage, 1991:97-9.

24 Berk RA. Determination of optimal cutting scores in criterion-referenced measurement. Fournal of Experimental Education 1976;45:4-9. 